\title{
Correction to: Advancing the Circular Economy in Public Sector Organisations: Employees' Perspectives on Practices
}

\author{
Natacha Klein ${ }^{1}$ - Tomás B. Ramos ${ }^{1}$ - Pauline Deutz ${ }^{2}$
}

Published online: 28 July 2021

(C) Springer Nature Switzerland AG 2021

\section{Correction to: Circular Economy and Sustainability https://doi.org/10.1007/s43615-021-00044-x}

The original article has been corrected. Table 7 was incorrectly represented in the original publication. Please find here the correct table:

The online version of the original article can be found at https://doi.org/10.1007/s43615-021-00044-X

Natacha Klein

n.klein@ campus.fct.unl.pt

1 CENSE-Center for Environmental and Sustainability Research, Department of Environmental Sciences and Engineering NOVA School of Science and Technology, NOVA University Lisbon, Lisbon, Portugal

2 Department of Geography, Geology and Environment, University of Hull, Hull, UK 


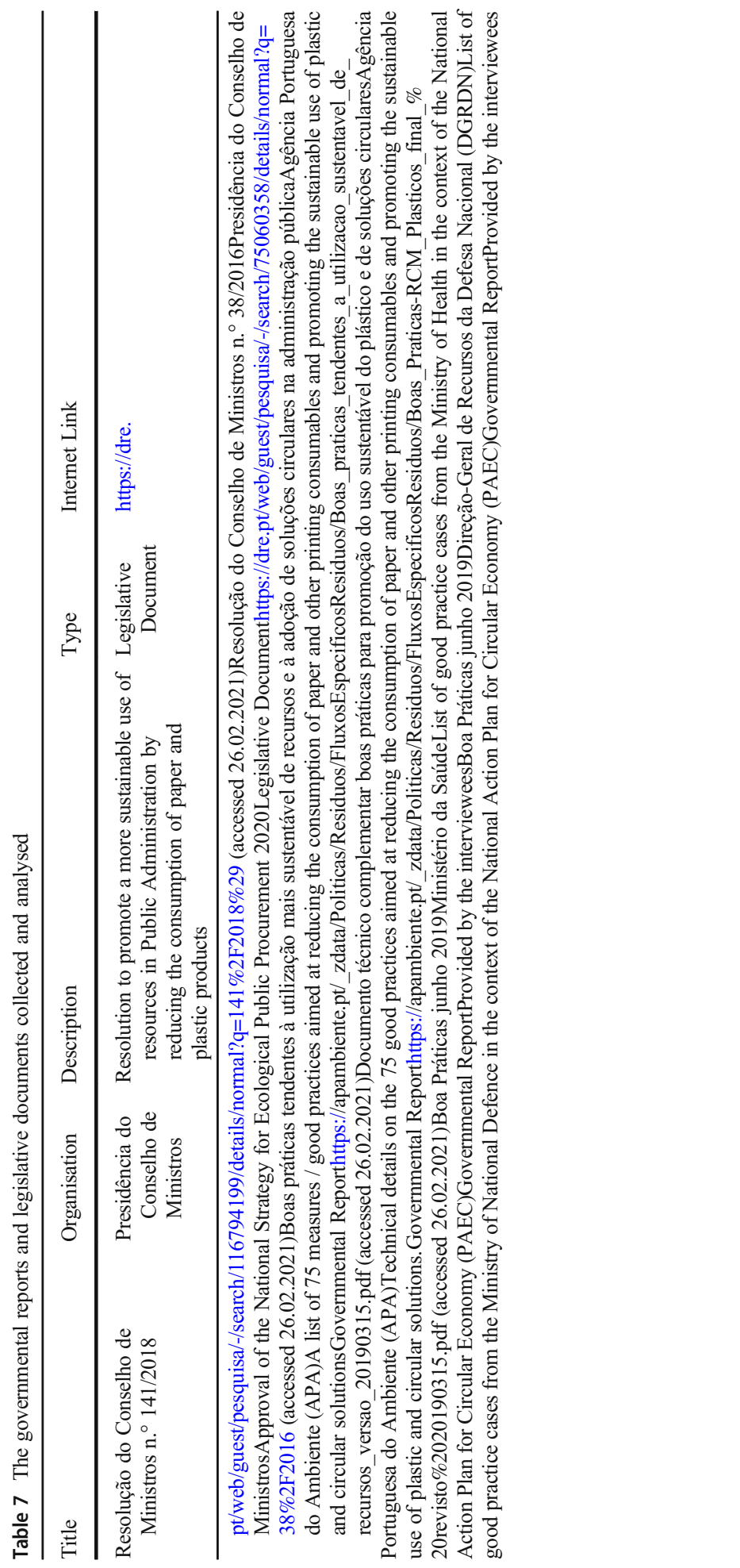


